\title{
A disputa nos governos estaduais (1994-2014): a batalha entre incumbents e oposição
}

Maurício Michel Rebello

\section{Introdução $^{1}$}

A ciência política brasileira tem se dedicado pouco à análise sobre as oposições aos governos no país. Quando se trata de unidades subnacionais, tal déficit se torna ainda mais claro. Em geral, compreende-se que o sistema partidário brasileiro possui enorme dependência em relação a postos governamentais, sendo interpretado o Poder Executivo como o eixo gravitacional do sistema político (Santos, 2006; Amorim Neto, 2007). Em toda reforma política debatida, sempre se insere a discussão de como frear o poder de alguns atores, como governadores e, principalmente, o governo federal. Diante disso, desde 2016 debate-se no Congresso Nacional o fim da reeleição para cargos Executivos ${ }^{2}$.

O argumento de que as organizações partidárias dependem cada vez mais de recursos estatais não é algo novo na política, isto é indicado, por exemplo, na tese sobre a cartelização do sistema partidário europeu (Mair, 1997; Blyth e Katz, 2005). A disputa eleitoral, mas sem os recursos partidários de outrora - como militantes, financiamento parlamentar, financiamento de filiados -, faz com que os partidos políticos busquem novas formas de sobrevivência (Krause, Rebello e Silva, 2015). Assim, a proximidade partidária com o governo, e consequentemente com o Estado, pode criar incentivos para que os atores políticos busquem a vitória em postos estaduais, diminuindo a rotatividade de poder que se exige em uma democracia.

Estudos sobre sistemas políticos estaduais existem (Lima Jr., 1993; Abrucio, 1998; Santos, 2001; Cardello, 2009; Melo, Pereira e Werneck, 2010; Inácio e Amaral, 2013), mas ainda são poucos quando comparados com pesquisas sobre o sistema político nacional. Muitos deles situam apenas alguns casos e abrangem poucos anos, não permitindo comparações sobre as diferentes realidades de um país heterogêneo como o Brasil. Neste artigo, pretende-se preencher parcialmente tal lacuna, analisando todas as unidades da federação em uma análise longitudinal que abrange um período de duas décadas. Pretende-se, também, demonstrar a existência de grupos partidários com forte permanência nos governos estaduais, mas, simultaneamente, mostra-se como a maioria

\footnotetext{
${ }_{1}^{1}$ Agradeço muito aos comentários dos pareceristas, que foram fundamentais na melhora do artigo.

2 No dia 27 de maio de 2015 a Câmara dos Deputados, por 452 votos favoráveis a 19 votos contrários, aprovou o fim da reeleição para cargos do Executivo. O texto ainda não foi votado pelo Senado. Disponível em: <http://www2.camara.leg.br/camaranoticias/noticias/politica/489068-camara-aprova-fim-dareeleicao-para-presidente,-governador-e-prefeito.html>. Acesso em: 25 jun. 2015.
} 
das eleições permite que novos nomes sejam lançados, não existindo um padrão de reeleição muito expressivo.

O artigo está dividido em quatro partes. Na seção "O espaço do governo e da oposição no sistema político brasileiro", realiza-se uma discussão de como a relação entre governos e suas coalizões impacta os atores que permanecem na oposição. Em geral, acredita-se que o sistema político produza mais incentivos para que os partidos políticos sejam aliados a uma coalizão governista do que para desafiá-la. Em "Procedimentos metodológicos", realiza-se uma discussão da metodologia adotada. Em "Análise dos dados", abordam-se os dados, mostrando como existem elementos contraditórios entre o instituto da reeleição e a permanência de grupos políticos no poder, matizando algumas análises mais apressadas. Por fim, nas "Considerações finais", faz-se um balanço dos resultados com as principais análises acerca dos problemas da estrutura política no Brasil.

\section{O espaço do governo e da oposição no sistema político brasileiro}

Neste artigo, o quadro teórico parte de estudos que privilegiam os partidos políticos como modelos analíticos (Duverger, 1970; Kirchheimer, 1966; Panebianco, 2005; Mair, 1997). Nesse sentido, compreende-se que há uma lacuna sobre o modelo partidário ideal para fins analíticos. Em outras palavras, não existe consenso dos estudiosos se a tese de cartelização se sobrepõe totalmente ao modelo de partido catchall, nem mesmo sobre a possível perda do sentido histórico quanto ao uso do modelo de massas duvergeriano para um estudo contemporâneo dos partidos (Wolinetz, 2002).

A partir de um modelo clássico exposto por Maurice Duverger, na década de 1950, a literatura sobre partidos políticos se utiliza deste para comparar com outros modelos partidários. O partido de massas clássico se define, basicamente, por: contexto da primeira metade do século $X X$, contexto de ampliação do sufrágio, surgimento ou consolidação dos partidos trabalhistas, operários e comunistas, financiamento próprio a partir dos militantes, ideologia claramente demarcada e sobreposição entre classe social e voto.

Algumas décadas depois do estudo de Duverger, já haviam sido diagnosticadas mudanças no sistema partidário que já não mais se enquadrariam no clássico partido de massas. Diante disso, Angelo Panebianco, no início da década 1980, retomando um ensaio produzido por Otto Kirchheimer (1966), confirma algumas mudanças no cenário europeu: redução da clareza ideológica, ampliação de financiamento a vários setores de interesse, menor papel do militante, enfraquecimento da classe gardée e crescimento da autonomia das lideranças. Tais características abrangem o chamado modelo catch-all.

Por último, na década de 1990, autores como Richard Katz e Peter Mair indicaram mais mudanças nas características partidárias do final do século, sugerindo outra tipologia: o partido cartel. Encontrar-se-ia nesse novo século: ausência de conteúdos 
programáticos, ausência de objetivos eleitorais entre as legendas, financiamento mediante fundos públicos, perda do caráter representativo e, por fim, altas taxas de abstenção eleitoral. Além disso, os partidos políticos seriam quase que o próprio Estado e não mais agentes de ligação entre sociedade civil e Estado, por isso, a noção de cartel, importada da administração.

A última consideração feita - aproximação das organizações com o Estado fortalece modelos analíticos que compreendem como ser governo, e, consequentemente, conquistar o Estado, é peça-chave na estrutura política brasileira. A bibliografia brasileira sempre foi enfática ao argumentar o peso de ser/estar na arena governamental. Possivelmente, já no primeiro trabalho moderno da ciência política brasileira Coronelismo, enxada e voto - o peso dos postos estaduais indicava como ser governo importa, tanto para afastar concorrentes como para estreitar alianças (Leal, 2012).

Como modelo teórico, o partido cartel poderia se encaixar perfeitamente no caso brasileiro se se tornar claro que aos partidos políticos não importa tanto ganhar ou perder uma eleição no Executivo, mas sim estar junto do governo. O governismo, nessa seara, poderia ser posição mais cômoda para atrair recursos estatais. Para tanto, deverse-ia estudar o comportamento dos partidos diante dos governos, por isso a importância de estudos em unidades subnacionais a fim de verificar se isso tem respaldo empírico. Como modelo teórico, um dos poucos estudos que se propôs a replicar tal bibliografia internacional para o Brasil ainda é o de Mainwaring (2001), no qual afirma que a maioria das legendas brasileiras seria próxima de um modelo catch-all. O Brasil seria o reino dos catch-all parties, segundo suas palavras.

A ciência política brasileira dos últimos anos permitiu um grande ganho de conhecimento acerca do comportamento dos atores partidários e das nossas instituições. Se no início da década de 1990 diagnósticos sombrios acerca da ingovernabilidade eram comuns (O’Donnell, 1992; Lamounier, 1993; Kinzo, 1993; Mainwaring e Scully, 1994), foi somente a partir do final da mesma década que um ponto confluente da ciência política surgiu: não existe, necessariamente, ingovernabilidade no Brasil (Figueiredo e Limongi, 1999; Palermo, 2000; Santos; 2003). A conquista de várias coalizões de governo com alguma disciplina permitiu maior estabilidade política do país e menor espaço para visões pessimistas dos cientistas políticos. Evidentemente, a disputa em torno do nexo causal sobre como se atinge a governabilidade ainda é variada entre diversos modelos, principalmente entre o modelo partidário e o distributivista (Carvalho, 2003).

Não obstante o grande avanço da área comparativamente ao vazio de estudos de décadas passadas, uma lacuna ainda permanece: nesse emaranhado de coalizões de todos os tipos e famílias, como ficam aqueles atores que desafiam a lógica governista e se colocam como oposição? Passadas quase três décadas desde a redemocratização, embora existam estudos publicados nessa seara - como se verá a seguir - ainda são poucos quando comparados com análises sobre os governos e suas coalizões. 
Algumas análises atuais instigam a pensar se vale a pena ser oposição no Brasil (Meira, 2012; Rebello, 2013; Peres, 2014; Carvalho e Figueiredo Filho, 2014). Quando um partido político, não pertencente à coligação eleitoral vitoriosa para postos executivos, começa um novo mandato, deve fazer a opção de vir ou não a integrar o governo. No caso do governo federal, desde a redemocratização, o apoio obtido pelos presidentes tem sido crescente, isto é, cada vez menos organizações se assumem como oposição (Peres, 2014). O afastamento da condição de oposição é apontado claramente como uma falta de estímulo em termos de recursos partidários. Em outras palavras, o Executivo no Brasil exerce um grande poder de atração aos partidos políticos (Santos; 2006; Amorim Neto, 2007). São vários os fatores que explicam essa aproximação, sendo o maior deles o potencial de recursos orçamentários e os cargos de prerrogativa do Poder Executivo. Em sentido contrário, qual seria o benefício em ser oposição? No atual sistema político, o maior benefício deveria ser o de se contrapor às políticas do Executivo visando à conquista do poder na próxima eleição. Entretanto, em um ambiente de alta fragmentação partidária, torna-se difícil a oposição obter um relevante destaque. Em países com alta fragmentação partidária e com governos de coalizão, por exemplo, é mais difícil definir quem é responsável pelo governo (Powell, 2000; Samuels, 2004).

Os partidos políticos governistas não precisam, necessariamente, se apresentar enquanto tal em uma eleição. Quando há uma aproximação de novo pleito eleitoral, alguns partidos passam à oposição e realizam um discurso de concorrentes ao partido incumbent ${ }^{3}$, mesmo tendo pertencido à coalizão anterior. Nas últimas duas eleições presidenciais, por exemplo, a candidatura de Marina Silva pelo PV, em 2010, e pelo PSB, em 2014, evidencia tal condição, nas quais as respectivas legendas formavam a base de sustentação de Lula II e Dilma I, mas, mesmo assim, adotaram um discurso de oposição durante a eleição. Assim sendo, governos mal avaliados podem ser sucedidos por partidos políticos que estavam na condição de governo - e isso é bem comum, como é revelado mais adiante. Evidentemente, há casos clássicos em sentido oposto, como o PT, que foi oposição por muitos anos a todos os governos federais desde a redemocratização e conquistou a presidência em 2002.

A principal arena da oposição é o Legislativo, contudo, parte da bibliografia compreende que tal Poder tem suas atribuições diminuídas frente ao Executivo (Moisés, 2011). De fato, desde a publicação do trabalho de Figueiredo e Limongi (1999), são vários os indicativos do limitado papel do Congresso Nacional ante a agenda do Executivo. Individualmente, por exemplo, um parlamentar tem um espaço muito reduzido no transcorrer de seu mandato. No caso brasileiro, são várias as prerrogativas do Executivo que garantem não só a implementação de uma agenda praticamente

\footnotetext{
3 A palavra incumbent pode ter diversos significados. No Brasil, a palavra incumbente, apesar de não existir na língua culta padrão, está associada à palavra incumbência, ato de incumbir alguém sobre determinado cargo, tarefa ou missão (Dicionário da Academia Brasileira de Letras, 2008). No caso do significado norte-americano, é aquele que ocupa determinado cargo (mandatário). Neste artigo, utiliza-se a palavra para se referir ao governo tanto no Executivo como no Legislativo (coalizão de governo).
} 
A DISPUTA NOS GOVERNOS ESTADUAIS (1994-2014): A BATALHA ENTRE INCUMBENTS E OPOSIÇÃO

unilateral como também a aprovação frequente de suas proposições enviadas ao Congresso Nacional. Capacidade de editar medidas provisórias, leis de caráter de urgência e prerrogativas orçamentárias próprias, capacidade de vetar parcialmente projetos de lei, aliadas a uma capacidade razoável de fazer com que as legendas presentes no Congresso cooperem com o Executivo fazem do presidente um ator central no sistema político.

Ao utilizar dados do Basômetro, Peres (2014) mostra a alta taxa de governismo ao longo dos governos petistas (77\%) na Câmara dos Deputados. No Senado, no governo Dilma, a taxa de sucesso é ainda mais alta, com $84 \%{ }^{4}$. Quando considerados somente os partidos que formavam a base de sustentação (na maior parte do tempo) ao longo dos governos petistas, como PT, PC do B, PSB, PDT, PMDB, PTB e PP, a taxa é sempre superior a $84 \%$, sendo PT e PC do B os mais fiéis, com valores acima de $94 \%$ (Carvalho e Figueiredo Filho, 2014).

Não obstante o governismo, existem críticas metodológicas que devem ser observadas quando se analisam votações nominais na Câmara. A primeira crítica é a de Ames (2003), na qual afirma que muitas das proposições do Executivo não vão à votação em plenário por não existir consenso prévio entre as lideranças partidárias, impedindo uma adoção da vontade ótima do governo. Além disso, dentro do universo das votações nominais consideradas, devem ser excluídas aquelas quase consensuais (com mais de $90 \%$ de votos), algo que não é feito pelo Basômetro. Quando consideradas as taxas de governismo segundo tal critério, e ainda incluindo as abstenções, o indicador despenca para em torno de $45 \%$ a $50 \%$ ao longo dos governos petistas (Santos e Canello, 2014). Contudo, como salientado pelos autores, tais ausências podem não ser sinônimos de fracasso do Executivo, até mesmo porque em algumas proposições não é exigido quórum especial. Em geral, a interpretação corrente da ciência política é de que continua difícil o governo ser derrotado nas votações nominais do Congresso Nacional (Figueiredo e Limongi, 1999; Moisés, 2011).

Mesmo com um menor papel do parlamento, a oposição ainda obtém alguns instrumentos importantes nas casas legislativas segundo o modelo Constitucional de 1988, entre eles: obstrução parlamentar legítima, emendas a projetos, mudança de pauta, questões de ordem e reclamação, CPIs, solicitação de investigação ao TCU, convocação de ministros de Estado para audiências públicas e Propostas de Fiscalização e Controle. A maioria de tais instrumentos não contém mecanismos para alterar o status quo, contudo, em diversas vezes, eles servem como um constrangimento às posições de governo. Algumas servem para atrasar as votações de propostas do governo, como emendar projetos ou obstruir pautas. Ainda que o desejo das maiorias se mantenha, as oposições, geralmente minoritárias desde a redemocratização, possuem mecanismos importantes frente aos governistas, demarcando, por vezes, uma clara oposição programática em termos de políticas públicas (Bezerra, 2012).

\footnotetext{
${ }^{4}$ Os dados vão até 2012.
} 
A Constituição brasileira permite que minorias recorram ao Supremo Tribunal Federal (STF) com pedidos de Ações Diretas de Inconstitucionalidade (Adins) adicionando um veto player importante para a oposição. Assim, chama-se o Poder Judiciário para intervir em decisões extremamente importantes. Entre 1995 e 2008, por exemplo, ocorreram mais de 900 pedidos de Adins, com preponderância no governo FHC (Taylor e Da Ros, 2008). Além de partidos políticos, as mesas do Senado, da Câmara e das Assembleias, os sindicatos, as federações, os governadores, entre outros, também podem solicitar pedidos de Adins, fazendo com que esse instrumento seja de vital importância para atores externos ao jogo político entre coalizão e oposição no Congresso Nacional (CF, art. 103). Entre o período de 1995 e 2008, 33\% do total de Adins contra leis federais implicaram alguma alteração de legislação, além disso, a grande maioria dos partidos políticos que protocolaram esses pedidos era de membros da oposição, assim, o STF se torna um canal importante para as minorias (Taylor e Da Ros, 2008).

No caso de unidades subnacionais, a situação da oposição não parece ser confortável. No caso dos governadores estaduais, a dissertação de Abrucio (1998) destaca a grande autonomia dos estados brasileiros em nosso arranjo federativo, principalmente no período da República Velha. Apesar de admitir o contínuo fortalecimento do poder central desde 1930, Abrucio ainda acentua a força política dos governadores no período da redemocratização. Segundo o autor, os governadores teriam a sua disposição a distribuição de empregos públicos, a distribuição de verbas públicas e uma grande parcela de controle não só de deputados estaduais - os quais formavam coalizões governistas generosas -, mas também de deputados federais e prefeitos. Apesar da inegável força política de alguns governadores em nível local, o estudo de Abrucio não ponderou adequadamente as mudanças que estavam em curso, como o aumento do endividamento dos estados, a quase extinção dos bancos estaduais e, principalmente, um percentual de arrecadação tributária nacional pequeno para os governos estaduais (cerca de $25 \%$ ) quando comparado ao governo federal (cerca de 60\%) (Arretche, 2000).

Em nível estadual, a decisão dos deputados estaduais em ser ou não governo não é unívoca, depende de fatores como a relação do partido com o governador, a força do partido, a base eleitoral dos deputados, o calendário eleitoral, a popularidade do governador. Ainda assim, quando analisados 12 estados da federação, a maioria dos deputados estaduais teve uma inclinação governista, ainda que moderada (Inácio e Amaral, 2013). Quanto maior a importância de recursos orçamentários para a base eleitoral de um deputado, maior é a sua dependência em relação ao Executivo, tornando um parlamentar mais propício ao governismo (Inácio e Amaral, 2013). Em análise sobre coalizões estaduais, entre 1997 e 2003, todos os governos estaduais possuíam coalizões. Em média, 66\% dos deputados das Assembleias Legislativas apoiavam o governador e o número médio de partidos na coalizão era de 6,5. Desse modo, o governismo ficou evidente nesse período (Melo, Pereira e Werneck, 2010). 
A DISPUTA NOS GOVERNOS ESTADUAIS (1994-2014): A BATALHA ENTRE INCUMBENTS E OPOSIÇÃO

A influência de recursos orçamentários na taxa de sucesso dos partidos acaba por ser um fator crucial na escolha entre ser governo ou ser oposição. Exemplo disso são as coligações eleitorais vitoriosas para os cargos de governador e senador. Quando reunidas essas duas coligações, sua taxa de sucesso é sensivelmente maior quando a coligação é composta somente por partidos do governo federal do que quando composta por partidos de oposição ao governo federal. Além disso, as candidaturas de governadores que apoiam o governo federal representam uma taxa de sucesso superior em cinco vezes às candidaturas de oposição (Carreirão e Do Nascimento, 2010).

Quanto ao sucesso eleitoral daqueles que apoiam o governo, há indicativos de que pertencer à base do Executivo é mais positivo do que negativo. Desde que a Emenda Constitucional no 16, de 1997, foi promulgada, permitindo a reeleição imediata para cargos executivos, já houve muito debate acerca dos benefícios e malefícios causados com esse novo dispositivo constitucional. Para alguns analistas, a reeleição introduz um fator de desequilíbrio a favor do candidato à reeleição, com destaque para: o timing, na qual o candidato incumbent já está em campanha ao longo do mandato, volume de recursos superior e um potencial maior de propaganda (Lavareda, 2011). É mister salientar que o favorecimento a pessoa do incumbent acaba, geralmente, por favorecer o partido incumbent. Ainda assim, há debates interessantes: será que o partido sempre é favorecido em caso da reeleição de um chefe de Executivo? Nos cargos para o Legislativo ele foi favorecido, por exemplo? Nem sempre o prejuízo ou ganho eleitoral de um partido no Executivo acompanha seu desempenho no Legislativo, principalmente em locais com alto número de partidos políticos e grandes coalizões (Marenco, 2009; Rebello, 2013).

Ainda que o instituto da reeleição contribua para a eleição dos que se recandidatam, deve-se observar certo resguardo ao afirmar que a reeleição acaba por favorecer a permanência de um mesmo grupo político no poder. Um dos problemas metodológicos no cálculo da reeleição é que, geralmente, são considerados somente aqueles que se recandidatam. Caso haja a inclusão de todos os concorrentes aos cargos, observa-se a taxa de renovação, que é razoavelmente elevada (Cardello, 2009).

Quanto às unidades subnacionais, existem estudos pioneiros no Brasil sobre os subsistemas partidários (Lima Jr., 1993). Em um país de dimensão continental, menosprezar a especificidade local de vários subsistemas partidários impede uma visão compreensiva sobre o nosso sistema político. A simples análise pura de dados agregados nacionais esconde enormes diferenças nas disputas estaduais (Lima Jr., 1993). Exemplo é a questão da competição. Em muitas unidades subnacionais, alguns partidos políticos concentram bastante de sua força política, como foi o caso do PFL na região Nordeste ao longo da década de 1990. Nesse sentido, nosso artigo, ao focar a disputa de governos estaduais, pode contribuir para verificar padrões distintos no tocante à relação entre governo e oposição em nível local.

Toda a discussão acima demonstra pontos ainda não claros: ser governo permite uma hegemonia política clara? A oposição realmente está em dificuldades no país? Ao levantar essas perguntas, prossegue-se para a próxima parte, na qual é considerada a 
MAURÍCIO MICHEL REBELLO

situação das candidaturas a governador segundo o grau de participação no governo anterior.

\section{Procedimentos metodológicos}

Para a realização do artigo, construiu-se um banco de dados (SPSS) com as eleições para os governos estaduais entre 1994 e 2014, abrangendo 162 eleições analisadas. As eleições de 1990 não foram consideradas pelo banco, mas seus dados foram utilizados para averiguar quem era governo nas eleições de 1994. A opção de não incluir a eleição de 1990 se deve ao fato de que, em 1986, quase todos os governadores foram eleitos pelo PMDB, o que geraria um viés na análise das eleições de 1990. A fonte utilizada foi o Tribunal Superior Eleitoral (TSE) 5 .

Este artigo não se propõe a realizar modelos estatísticos de análise, pois não há interesse em explicar a ocorrência de nenhuma variável dependente, tanto o é que, apesar de ter considerações sobre o assunto, opta-se por desconsiderar possíveis hipóteses previstas na literatura. Assim, são realizadas somente análises descritivas de dados.

Para que se possa compreender o jogo de poder entre partidos, foi essencial analisar a ocorrência das reeleições possíveis desde 1994. Também se averigua o desempenho dos partidos políticos em nível subnacional. Desse modo, em cada eleição, analisa-se quem é o partido vencedor e seu respectivo desempenho (tanto no primeiro como no segundo turno). Em alguns casos, apesar de a reeleição não se mostrar relevante em alguns estados, a força política de alguns partidos é relevante (Cardello, 2009).

Outra variável incorporada foi a inclusão das coligações. Muitos estudos podem ser feitos a partir da pesquisa sobre coligações partidárias. Um exemplo que se observa é o crescente uso de coligações para a vitória dos candidatos a governador, com uma inclusão de coligações cada vez mais heterogêneas ideologicamente (Krause e Godoi, 2010). A partir disso, pode-se identificar se existe uma espécie de cartel no poder, com a vitória não do mesmo partido, mas de um conjunto de partidos. Isso permite verificar se partidos exógenos a essa coligação conseguem triunfar nas eleições, permitindo uma maior rotatividade de poder nos estados.

Na literatura da ciência política é muito comum encontrar padrões totalmente distintos quanto à participação no governo. Nessa seara, acredita-se bastante que alguns partidos políticos, como o $\mathrm{PT}$, por exemplo, possuem menores incentivos à participação no governo (Hunter e Power, 2007). Em contrapartida, legendas conservadores teriam maior "vocação" para comportamentos pró-governo (Mainwaring, Meneguello e Power,

\footnotetext{
${ }^{5}$ Agradeço a Jairo Nicolau o envio de um banco auxiliar feito por ele, que contém as mesmas informações do TSE, contudo, muito mais organizadas, o que resultou em grande ganho de tempo.
} 
A DISPUTA NOS GOVERNOS ESTADUAIS (1994-2014): A BATALHA ENTRE INCUMBENTS E OPOSIÇÃO

2000). Assim sendo, o banco de dados também inclui os padrões de permanência no governo que existem nos principais partidos políticos brasileiros.

A partir da noção de subsistemas partidários (Lima Jr., 1993), enfatizam-se algumas dimensões regionais e estaduais sobre a força política de alguns grupos. Ao que tudo indica, a competição política local altera bastante o perfil do tipo de elite política. Em algumas regiões, por exemplo, o comportamento eleitoral não permite falar em máquinas partidárias, já que a rotatividade do poder é grande. Assim, inclui-se uma variável de cunho regional.

Ainda que incipiente, a inclusão de uma compreensão maior quanto a quem é governo busca sair de uma leitura mais simplista sobre qual partido está no poder em determinado período. Isso poderia mostrar, por exemplo, se quase não há alternativa para grupos políticos historicamente alijados do poder, indicando uma cartelização (Mair, 1997). Ao longo das tabelas, são descritos os procedimentos adotados.

\section{Análise dos dados}

Como discutido anteriormente, o grau de permanência de um mesmo grupo político no poder é uma variável importante nas democracias. Segundo Dahl (1997), um dos eixos da democracia é a capacidade de contestação pública, em que a oposição tem papel importantíssimo. Atores políticos contrários aos governos atuais devem ter uma oportunidade de postular postos no Estado. Alguns indicadores de democracia - como o índice de Vanhanen, por exemplo - avaliam quanto existe de compartilhamento de votos pelos partidos, indicando que a alta predominância de um grupo pode tornar o sistema menos democrático (Norris, 2008).

No caso dos governos estaduais no Brasil, uma importante parte da bibliografia indica extensas prerrogativas por parte dos governadores, tornando-os atores muito importantes no sistema político (Abrucio, 1998). A inclusão da Emenda Constitucional no 16, que permitiu a reeleição imediata de postos do Executivo (presidência, governos estaduais e prefeituras), demarcou um debate que se mantém até hoje em algumas propostas do Congresso Nacional de erradicar esse dispositivo. O motivo seria o amplo favorecimento do detentor do cargo em relação aos seus concorrentes (Lavareda, 2011). Em oposto, algumas pesquisas que analisaram municípios indicam que não existe motivo para o fim da reeleição (Brambor e Ceneviva, 2012).

A Tabela 1 mostra o instituto da reeleição em todas as eleições para governador. Um comentário metodológico importante é que foi considerado como candidato incumbent somente o governador no momento eleitoral. Ou seja, eventuais desistências, mortes ou processos de afastamento não foram considerados. Assim, não são tidos como incumbents os vice-governadores que, ao longo do mandato, assumiram o governo estadual e se candidataram na eleição subsequente. A adoção desse procedimento ocorre porque considerar como incumbents vice-governadores que assumiram ao longo do mandato exigiria um esforço analítico maior e causaria certo impasse, pois, dever-se-ia 
levar em conta um período mínimo - metade do mandato, por exemplo - para ser definido como incumbent, afinal não faz sentido um governador ter menos de seis meses de mandato e ser considerado incumbent. No total, são poucos casos e não representam maiores problemas metodológicos.

Tabela 1

Reeleição dos governadores no Brasil (1998-2014) (\%)

\begin{tabular}{|l|c|c|c|c|c|c|}
\hline \multirow{2}{*}{ Situação } & \multicolumn{5}{|c|}{ Anos } & \multirow{2}{*}{ Total } \\
\cline { 2 - 6 } & 1998 & 2002 & 2006 & 2010 & 2014 & \\
\hline Governadores que se recandidataram & 70,4 & 29,6 & 59,3 & 33,3 & 44,4 & $\begin{array}{c}47,4 \\
(64)\end{array}$ \\
\hline $\begin{array}{l}\text { Governadores reeleitos dentre os que } \\
\text { se recandidataram }\end{array}$ & 68,4 & 75 & 75 & 77,8 & 66,7 & $\begin{array}{c}71,9 \\
(46)\end{array}$ \\
\hline $\begin{array}{l}\text { Taxa de renovação sobre o total de } \\
\text { eleições }\end{array}$ & 51,9 & 77,8 & 55,6 & 74,1 & 70,4 & $\begin{array}{c}65,9 \\
(135)\end{array}$ \\
\hline
\end{tabular}

Fonte: Elaboração própria com base em dados do TSE. Entre parênteses o número total.

Deve-se tomar muito cuidado com a interpretação de tais dados. Dependendo do procedimento metodológico adotado, pode-se compreender que a reeleição favorece os incumbents. Entre aqueles que se recandidataram, a grande maioria (71,9\%) teve êxito. Em geral, todas as cinco eleições apresentam um bom retorno eleitoral aos governadores, variando de 77,8\%, em 2010, a 66,7\%, em 2014. Contudo, ao avaliar-se o número de novos governadores, isto é, a taxa de renovação, percebe-se algo bem diverso. A cada três eleições em quase duas, existem novos governadores.

Isso se deve, em grande parte, ao número de governadores que se recandidataram $(47,4 \%)$. Em média, uma maioria de governadores não tenta a reeleição. Os motivos são variados, mas o principal é que alguns já foram reeleitos e não podem mais concorrer na eleição subsequente. Note-se, por exemplo, que a cada eleição existe uma alta variação entre aqueles que se recandidatam. Em 1998, ano em que todos os governadores poderiam se recandidatar, 70,4\% o fizeram, já em 2002 o número cai para 29,6\%, em 2006 volta a subir (59,3\%), diminuindo em 2010 (33,3\%) para novamente aumentar em $2014(44,4 \%)^{6}$.

A simples reeleição de um nome não favorece, necessariamente, o partido incumbent. Em algumas reeleições, por exemplo, na qual se sucedem crises econômicas, a perda de representatividade e de tamanho do partido governista (seja em votos, seja em recursos, seja na sua capacidade de influenciar políticas públicas) pode vir a prejudicar um partido político - ainda que no caso brasileiro a clareza de responsabilidade seja menor (Marenco, 2009).

\footnotetext{
${ }^{6}$ Existe a possibilidade de que alguns governadores se tornem inelegíveis em função de pendência com a Justiça Eleitoral, mas isso não foi considerado no artigo.
} 
Por vezes, a capacidade de voto de uma figura política pessoal é muito maior do que a capacidade de voto do seu partido. Esse aspecto de "espetacularização" da política já foi bastante discutido na ciência política (Manin, 1995). A constatação da força personalista do voto no Brasil implica dizer que há favorecimento dos candidatos em detrimento dos partidos. Em geral, tal debate está associado a uma proposição de fim da lista aberta, que aumentaria, segundo seus propositores, a força dos partidos políticos no Brasil (Mainwaring, 2001).

Mesmo que houvesse o fim da reeleição, um cenário não tão improvável poderia existir: o repasse do capital político de um chefe de Executivo ao seu sucessor. Na história política brasileira é comum um candidato que não pode mais concorrer tentar passar seu capital político a outra pessoa - quando não da mesma família, como o caso do casal Garotinho. Desse modo, com o fim da reeleição, essas tentativas provavelmente se tornem mais frequentes.

Os dados de reeleição são contraditórios no caso dos governadores. Ao mesmo tempo em que se observa um razoável sucesso entre aqueles que se recandidatam, muitos nem tentam a reeleição. Não necessariamente porque não podem, mas porque desistem de fazê-lo. Possivelmente, deva existir uma correlação entre a popularidade dos governadores e a opção de se recandidatar, mas essa questão foge ao escopo desta análise. A Tabela 2 indica o desempenho de governadores e de concorrentes.

Tabela 2

Desempenho dos governadores (1998-2014) (\%)

\begin{tabular}{|l|c|c|c|c|c|c|}
\hline \multirow{2}{*}{ Desempenho } & \multicolumn{4}{|c|}{ Anos } & \multirow{2}{*}{ Total } \\
\cline { 2 - 6 } & 1998 & 2002 & 2006 & 2010 & 2014 & \\
\hline $\begin{array}{l}\text { Média de votos dos } \\
\text { governadores reeleitos (10 } \\
\text { turno) }\end{array}$ & 50,3 & 53,2 & 56,9 & 60,2 & 48,7 & $53,6(46)$ \\
\hline $\begin{array}{l}\text { Média de votos dos } \\
\text { governadores eleitos quando } \\
\text { não havia candidato à reeleição } \\
\text { (10 turno) }\end{array}$ & 57,1 & 46,7 & 48,8 & 51,6 & 51,4 & $50,4(71)$ \\
\hline $\begin{array}{l}\text { Governadores reeleitos no } \\
\text { primeiro turno entre os que se } \\
\text { recandidataram }\end{array}$ & 47,4 & 50 & 68,8 & 77,8 & 33,3 & $54,7(35)$ \\
\hline $\begin{array}{l}\text { Eleitos no primeiro turno } \\
\text { quando não havia candidato à } \\
\text { reeleição }\end{array}$ & 62,5 & 47,4 & 54,5 & 61,1 & 60 & $56,3(40)$ \\
\hline
\end{tabular}

Fonte: Elaboração própria com base em dados do TSE. Entre parênteses o número total.

Os dados indicam que ser governador não aumenta consideravelmente os votos no primeiro turno. A média de todo o período é de $53,6 \%$, o que indica um bom número de votos, mas como a maioria dos votos parte de um valor superior a $35 \%$, isso contribui 
MAURÍCIO MICHEL REBELLO

para uma elevação da média. Em geral, não há grandes variações por eleição. Comparando-se com os governadores eleitos onde não havia candidato à reeleição, a diferença é muito pequena. Nos anos de 1998 e 2014 há maior vantagem para concorrentes do que para os atuais governadores.

Somente pouco mais da metade $(54,7 \%)$ entre os que se recandidatam conseguem ganhar a disputa ainda no primeiro turno, evidenciando um bom grau de competitividade. Aqui, há uma grande variação em cada pleito, atingindo o pico em 2010 $(77,8 \%)$ e o mais baixo número em 2014 (33,3\%). Quando se compara com os pleitos onde não houve candidato à reeleição, percebe-se como não há grandes diferenças no total, embora em alguns anos o desempenho seja bem diverso - como o ano de 2014.

Considerando-se as Tabelas 1 e 2, qual deve ser a interpretação correta quanto a esses dados sobre o instituto da reeleição? Compreende-se, neste artigo, que a reeleição não cria uma barreira instransponível para que desafiantes venham a enfrentar o candidato incumbent. Evidentemente, não se pode menosprezar o peso de um candidato à reeleição, mas isso não impede a vitória de desafiantes. Além disso, é equivocado supor que sempre um reeleito obteve sua vantagem em função do cargo que ocupou. Características pessoais, como carisma, não se esgotam em um período de quatro anos, assim, a vantagem de tais concorrentes pode não possuir relação com o cargo (Brambor e Ceneviva, 2012).

A simples constatação de que existe alta renovação de governadores no Brasil não implica dizer que não existam problemas para a oposição. Como relatado anteriormente, existe uma bibliografia que questiona se o papel da oposição não pode estar sendo prejudicado (Meira, 2012; Rebello, 2013; Peres, 2014; Carvalho e Figueiredo Filho, 2014). Até aqui, as análises se centraram somente sobre o instituto da reeleição, mas como estipular a participação da oposição? Na Tabela 3, é analisado o grau de continuidade de partidos no poder para mensurar o quanto os governos estaduais realmente produzem de alterações significativas em seus grupos políticos, permitindo uma rotatividade no poder. Averiguam-se quatro categorias governistas, indo da maior para a menor. A primeira é se havia continuidade do partido incumbent, denominada candidatura incumbent (abrange tanto reeleitos como candidatos eleitos pelo mesmo partido, mas que não eram os governadores atuais); a segunda é se o partido vencedor pertencia à coligação eleitoral vitoriosa na eleição prévia, denominada candidatura governista; a terceira é se o partido vencedor era exógeno (não pertencia à coligação anterior), mas algum partido coligado havia realizado uma coligação com a candidatura vitoriosa anterior, denominada candidatura semigovernista; e, por fim, se todos os partidos da coligação vitoriosa não possuíam relação com o governo estadual, denominada candidatura exógena. 
A DISPUTA NOS GOVERNOS ESTADUAIS (1994-2014): A BATALHA ENTRE INCUMBENTS E OPOSIÇÃO

Tabela 3

A rotatividade de poder nos governos estaduais eleitos (1994-2014) (\%)

\begin{tabular}{|c|c|c|c|c|c|c|c|}
\hline \multirow[t]{2}{*}{ Situação vencedora } & \multicolumn{6}{|c|}{ Anos } & \multirow[t]{2}{*}{ Total } \\
\hline & 1994 & 1998 & 2002 & 2006 & 2010 & 2014 & \\
\hline $\begin{array}{l}\text { Candidatura } \\
\text { incumbent }\end{array}$ & 25,9 & 37 & 44,4 & 37 & 40,7 & 37 & $\begin{array}{r}37 \\
(60) \\
\end{array}$ \\
\hline $\begin{array}{l}\text { Candidatura } \\
\text { governista }\end{array}$ & 7,4 & 14,8 & 11,1 & 11,1 & 22,2 & 25,9 & $\begin{array}{l}15,4 \\
(25) \\
\end{array}$ \\
\hline $\begin{array}{l}\text { Candidatura } \\
\text { semigovernista }\end{array}$ & 22,2 & 11,1 & 25,9 & 33,3 & 22,2 & 25,9 & $\begin{array}{l}23,5 \\
(38) \\
\end{array}$ \\
\hline Candidatura exógena & 44,4 & 37 & 18,5 & 18,5 & 14,8 & 11,1 & $\begin{array}{l}24,1 \\
(39) \\
\end{array}$ \\
\hline Total & $\begin{array}{l}100 \\
(27)\end{array}$ & $\begin{array}{l}100 \\
(27)\end{array}$ & $\begin{array}{l}100 \\
(27)\end{array}$ & $\begin{array}{l}100 \\
(27)\end{array}$ & $\begin{array}{l}100 \\
(27)\end{array}$ & $\begin{array}{c}100 \\
(27)\end{array}$ & $\begin{array}{c}100 \\
(162)\end{array}$ \\
\hline
\end{tabular}

Fonte: Elaboração própria com base em dados do TSE. Entre parênteses o número total.

Existe um razoável grau de continuidade no poder quando se analisam os partidos políticos. Das candidaturas realmente incumbents, ou seja, em que a mesma organização partidária continua no poder, não há tanta continuidade assim, no total, $37 \%$ de todas as eleições representaram uma continuidade do mesmo grupo político. A eleição de 1994 foi a única em que menos de $37 \%$ dos partidos continuaram no poder. Provavelmente, a possibilidade de reeleição imediata, a partir da eleição de 1998, tenha favorecido um aumento nos anos subsequentes, com a eleição de 2002 tendo 44,4\% de governadores eleitos pelo mesmo partido de quatro anos antes. Quando consideradas as candidaturas governistas, percebe-se que, isoladamente, são as que ocorrem com menor frequência. No total, $15,4 \%$ das candidaturas das eleições para governos estaduais no Brasil representam uma relativa continuidade política. Apesar de partidos diferentes em uma coligação não representarem uma total continuidade, até mesmo porque há uma diferenciação ideológica entre as coligações no Brasil (Krause e Godoi, 2010), é evidente que existe certa sequência de governo. O quão governista foram essas legendas ao longo de quatro anos é impossível saber, mas o fato é que elas estavam presentes e apoiaram a eleição do atual governador estadual. A eleição com menor número de sucesso desse tipo de candidatura mais uma vez foi a de 1994. Na última eleição analisada, em contrapartida, mais de um quarto dessas candidaturas obteve sucesso.

Já em relação às candidaturas semigovernistas, o grau de sucesso é um pouco maior. No total, foram $23,5 \%$ das candidaturas ao longo das seis eleições estudadas. Tal candidatura já é mais difícil de ser considerada como governista, pois o partido do governador eleito não havia pertencido à aliança que deu a vitória ao governador atual. A quantidade dessas candidaturas tem uma boa variabilidade em cada eleição, com destaque para a eleição de 1998 , em que a presença de tal situação foi pequena $(11,1 \%)$, e a eleição de 2006 , quando um terço das candidaturas foi semigovernista. 
As candidaturas exógenas, as quais se poderiam estimar como as mais prováveis de serem de oposição, têm um número similar às candidaturas semigovernistas, com $24,1 \%$. Nas candidaturas de "oposição", um dado que se destaca é a sua queda, indo da candidatura mais expressiva numericamente em 1994 (44,4\%) até chegar à candidatura mais escassa em 2014, com 11,1\%. Se tal candidatura está associada com o sucesso da oposição, parece que cada vez mais não vale a pena compor uma coligação com partidos distantes do governador eleito. Assim, pode-se estimar que ser oposição ao governador pode não ser uma boa estratégia eleitoral para tomar o posto do Executivo estadual.

Evidentemente, o que melhoraria a pesquisa nesse campo seria conhecer as legendas que pertencem à coalizão dos governos estaduais. Infelizmente, tamanho levantamento é muito complexo e de difícil realização. Um dos poucos estudos nessa dimensão é o de Melo, Pereira e Werneck (2010). Contudo, os objetivos da pesquisa são bem diversos dos do presente artigo, os dados não possuem a sistematização necessária, são poucos e o período abrange somente alguns anos (de 1997 a 2004). Uma dificuldade em "saber quem é governo" consiste na opção metodológica praticada. A mais comum é a composição ministerial (Amorim Neto, 2007), mas também as votações nominais podem ser um bom indicador quando analisadas a partir da orientação do líder do governo (Moisés, 2011; Peres, 2014). Realizar tal procedimento nos estados e no Distrito Federal longitudinalmente ainda é um grande desafio para a ciência política brasileira.

Um cálculo adicional realizado foi o tempo médio dos partidos nos governos estaduais, que consiste na divisão do número de partidos que governaram uma unidade da federação por mandatos consecutivos, pelo período analisado (24 anos, considerando o término da legislatura de 2015-2018), e o resultado consistiu em uma média de 6,9 anos - diferenças estaduais serão vistas mais adiante. Esse número é bem equilibrado, indicando uma saudável alternância partidária nos governos estaduais. O problema maior não é, então, a continuidade partidária nos governos estaduais, mas talvez o enorme poder de atração dos governadores frente aos partidos políticos nas Assembleias. Assim, a ideia de que o Executivo seria o centro de gravidade do sistema político ainda permanece (Santos, 2006; Amorim Neto, 2007).

Os dados apresentados tornam passível a interpretação de que existe uma relativa continuidade de permanência no poder, o que nos coloca diante da discussão teórica anterior: qual o modelo partidário brasileiro que se aproxima dos dados apresentados? Primeiramente, é importante salientar a diluição ideológica por meio da clara tendência de os partidos realizarem coligações eleitorais cada vez mais extensas. Isso posto, o modelo partidário mais próximo poderia ser tanto o catch-all (Kirchheimer, 1966) como o modelo de partido cartel (Mair, 1997). Contudo, quanto ao aspecto de aproximação com o Estado, o conceito de partido cartel fica mais explícito.

O potencial de atração do governo é indicado como uma tendência mundial, com a tese de cartelização. Nessa tese, cada vez mais o sistema partidário europeu, por exemplo, formaria uma espécie de cartel entre as organizações partidárias, com uma 
A DISPUTA NOS GOVERNOS ESTADUAIS (1994-2014): A BATALHA ENTRE INCUMBENTS E OPOSIÇÃO

participação partidária mais concentrada entre os principais partidos políticos nos governos. Tais partidos, por sua vez, teriam necessidade de substituir as fontes de financiamento de outras épocas - como recursos oriundos da militância, de grupos de interesse - para fontes derivadas do Estado. Assim, para as máquinas partidárias seria imprescindível a ocupação do Estado (Mair, 1997; Blyth e Katz, 2005).

A ocupação do Estado em outros países não depende tanto de estar na função de governo. Já para o caso brasileiro, "as chaves" do Estado, no caso dos governos estaduais, se situam sob o domínio dos governadores. Secretarias estaduais, cargos políticos, empresas estatais, fundações públicas, sociedades de economia mista dependem de indicações realizadas pelo chefe do Executivo. Todas essas instituições possuem grande influência em políticas públicas, ainda mais considerando o impacto que um governo estadual pode ter sobre os próprios agentes econômicos - como as isenções fiscais e a chamada guerra fiscal. O isolamento da oposição partidária é visível nesse sentido. Desse modo, a aproximação com os governos estaduais é extremamente importante para as organizações partidárias. Caso a variável coalizão estadual pudesse ser incorporada neste artigo, talvez a eleição de uma coligação genuinamente de oposição se mostrasse residual. Destarte, a tese de cartelização se aproxima dos dados encontrados aqui.

O Gráfico 1 averigua o perfil dos principais partidos políticos quanto à rotatividade do poder, indicando qual a estratégia eleitoral das legendas quanto a sua participação governamental quatro anos antes. Há grande variedade de resultados, mostrando estratégias eleitorais bem distintas quanto à opção em ser ou não governo. Foram considerados apenas os partidos que obtiveram, ao menos, cinco governos estaduais no período analisado (1994-2014) ${ }^{7}$.

\footnotetext{
${ }^{7}$ Número de governos de cada partido: PT 23, PSB 20, PDT 8, PMDB 40, PSDB 39, PP 7, DEM 15.
} 
Gráfico 1

Rotatividade de poder por partido (1994-2014) (\%)

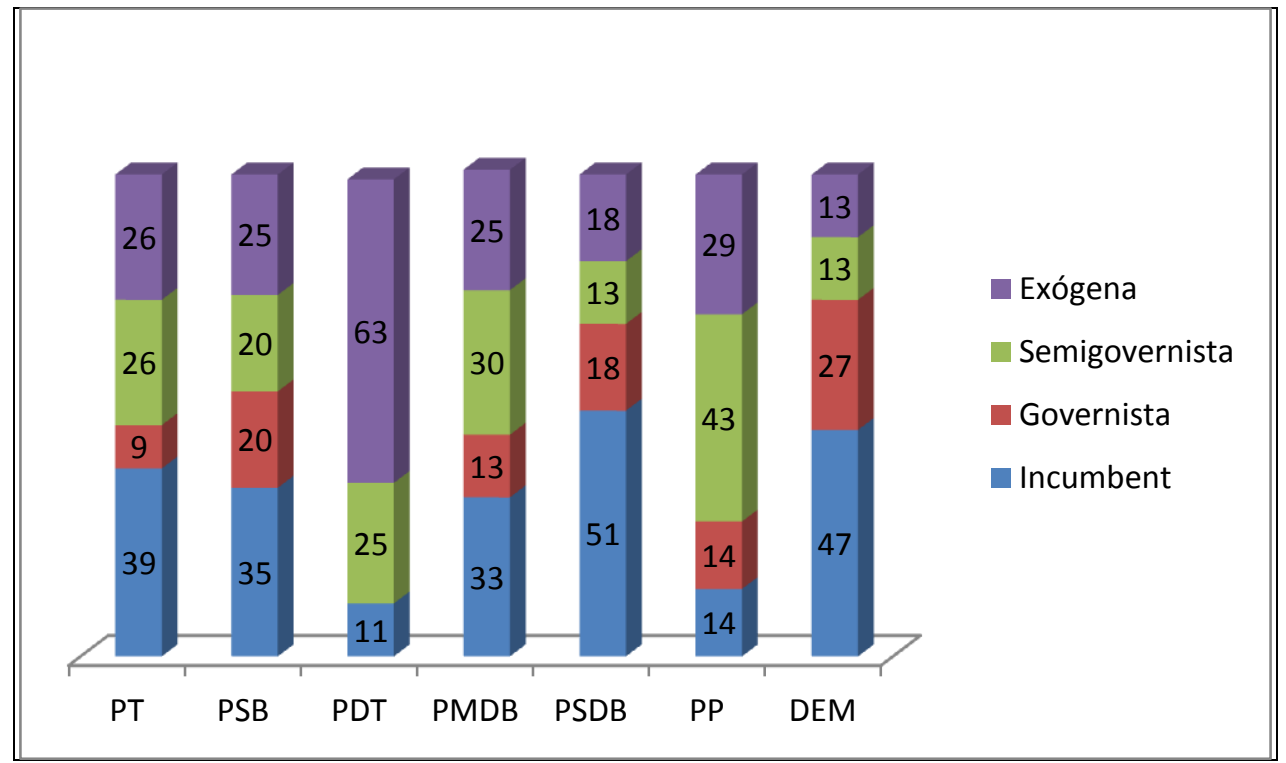

Fonte: Elaboração própria com base em dados do TSE.

Para facilitar a leitura do gráfico, os partidos políticos são colocados em ordem da esquerda para a direita (Tarouco e Madeira, 2015). No caso do PT, seu maior grau de sucesso se refere a candidaturas incumbents, assim como a maioria dos partidos. Ser partido coligado, mas não cabeça de chapa, não representa uma estratégia eleitoral representativa adotada pela organização ( $9 \%)$. Contudo, aliar-se com legendas que compunham a coligação eleitoral prévia é uma estratégia considerável (26\%), indicando maior maleabilidade do partido ao longo do tempo, com maior inclinação na aceitação das coligações (Krause e Godoi, 2010). Candidaturas totalmente exógenas, as quais podem ser consideradas como de oposição, também são significativas (26\%), mas menores do que candidaturas incumbents.

No caso do PSB e PDT, o perfil é bem diverso. Quanto ao PSB, seu perfil de candidaturas é similar ao do PT, mas com maior ênfase em ser coligado com o atual partido governista (20\%). Assim, a melhor estratégia socialista é ter algum vínculo governista, ou sendo o partido incumbent ou compondo a coligação eleitoral vitoriosa anterior. Ainda assim, um quarto das candidaturas não possui vínculo com a coligação eleitoral incumbent. O caso do PDT deve ser analisado com cautela. Apesar de ser a legenda que mais obteve sucesso quando sua coligação era exógena (67\%), o número de governos estaduais ganhos nesse período (apenas oito) dificulta melhor avaliação. De toda sorte, candidaturas incumbents do PDT não têm obtido sucesso (11\%), indicando dificuldades de continuidade do partido por um período superior a um mandato - isso somente ocorreu na reeleição de Waldez Goés no Amapá em 2006. 
Quanto aos partidos de centro, PMDB e PSDB, existem algumas diferenças. No caso do primeiro, o caráter governista não é tão pronunciado. Em somente uma a cada três eleições de governador, o PMDB se mantém como partido governante. Além disso, ter participado como coligação vitoriosa anterior não tem um grande peso para a legenda $(13 \%)$. Uma boa parte de suas vitórias possui uma coligação semigovernista (30\%), indicando poucos problemas de articular-se com partidos governistas. Contudo, ao contrário do que geralmente se pensa sobre a legenda (tida por alguns analistas como a agremiação mais governista de todo o sistema partidário), a eleição de alguns governadores com coligações totalmente exógenas não é irrelevante (25\%). Já o PSDB é o único partido no qual mais de $50 \%$ de seus governadores representam a continuidade do partido no poder, com São Paulo como grande contribuidor desse perfil -, com seis vitórias consecutivas. Em lado oposto, coalizões exógenas possuem um peso pequeno nos governos estaduais tucanos. Assim, o PSDB tem representado o partido de maior perfil governista no caso dos governos estaduais, alcançando grande êxito, em alguns estados, em conseguir manter um bom número de mandatos desde 1994 (São Paulo, Pará, Ceará, Goiás, Minas Gerais).

No caso da direita, o PP tem tido grande dificuldade em conseguir manter governos estaduais por muito tempo (14\%). Nem mesmo pertencer à coligação eleitoral vitoriosa tem tido grande impacto (14\%). Contudo, para o Partido Progressista, formar alianças com legendas governistas tem sido uma estratégia de maior sucesso entre os partidos (43\%). Em caso de legendas totalmente desvinculadas da coligação do governo anterior, o número é razoável (29\%). Já os Democratas, antigo PFL, tem perfil bem diverso. O DEM possui um perfil bem próximo de seu parceiro de coalizão na época do governo FHC, O PSDB. A maioria dos governadores eleitos dessa legenda representou a continuidade (47\%), com destaque para os casos da Bahia e do Maranhão. Quando consideradas as eleições nas quais o partido já fazia parte da atual coligação vitoriosa (27\%), pode-se dizer que o DEM fica na dependência de um perfil governista. Tal dependência faz com que apenas $13 \%$ de seus governadores sejam eleitos com somente partidos exógenos na eleição. O perfil governista dos Democratas pode significar sua total extinção caso continue como oposição ao governo federal, afinal, seus cargos eletivos têm diminuído sensivelmente (Epitácio e Resende, 2013).

A continuidade de um mesmo grupo partidário pode indicar ausência de uma cultura política de alternância, o que implicaria uma análise regional. Desse modo, o Gráfico 2 indica qual é o perfil das cinco regiões do país, indo da região mais governista para a menos governista: 


\section{Gráfico 2}

Rotatividade de poder por região (1994-2014) (\%)



Fonte: Elaboração própria com base em dados do TSE.

A região Nordeste é aquela que apresenta maiores possibilidades de sucesso para candidaturas incumbents. Metade dos governadores eleitos pela região representa uma continuidade partidária. Se somada com candidaturas governistas (15\%), quase dois terços das eleições nordestinas apresentam alta continuidade política. Candidaturas semigovernistas perfazem $19 \%$. Apenas $17 \%$ são governadores eleitos por coligações desvinculadas da eleição anterior. Assim, alguns estudos que demonstram como as máquinas partidárias são importantes na região nordestina podem estar corretos (Avelar e Walter, 2008).

A região Centro-Oeste, apesar de não possuir muitas eleições de partidos incumbents (29\%), é aquela que apresenta o maior número de eleições em que os partidos eleitos formavam a coligação anterior (29\%). Quanto a candidaturas exógenas, o número é baixo (17\%). A região Sudeste, por sua vez, também é bastante governista. É a região que mais se aproxima da nordestina (38\%) no que se refere a eleger partidos incumbents. São Paulo contribui bastante para isso, pois, com exceção de 1994, todas as outras eleições deram continuidade ao PSDB. Em contrapartida, é a região que elege menos partidos coligados com o governo anterior (8\%). A eleição de partidos exógenos não é tão desprezível (25\%). A região Norte apresenta um padrão similar à região Sudeste em termos de candidaturas incumbents (33\%) e governistas ( $8 \%)$. No Norte, 
candidaturas exteriores à coligação eleitoral vitoriosa têm um papel um pouco maior $(31 \%)$.

A região Sul é onde o governismo se mostra mais fraco. Somente $17 \%$ das eleições representaram a continuidade de uma legenda, e, em $11 \%$ delas, a legenda vitoriosa era coligada com o governador. Candidaturas semigovernistas têm um peso considerável, com um terço das eleições apresentando tal perfil. No entanto, são as coligações exógenas o mais comum nessa região, mostrando alto grau de alternância dos grupos políticos estaduais. O caso do Rio Grande do Sul se mostra o mais radical nesse sentido, estado onde não houve nenhuma continuidade partidária e em apenas uma ocasião - a eleição do PSDB em 2006 - o partido eleito pertencia à coligação anterior.

A alta continuidade de partidos em alguns estados pode estar relacionada com o poder de famílias e de indivíduos. O personalismo e o familismo não são fenômenos estranhos ao comportamento eleitoral brasileiro segundo alguns estudos (Nicolau, 2006; Leal, 2012). Nesse sentido, buscaram-se sobrenomes e pessoas que conquistaram ao menos três eleições no período entre 1994 e 2014, visualizando famílias e indivíduos com hegemonia política local.

Quadro 1

Governadores e famílias com alto número de mandatos (1994-2014)

\begin{tabular}{|l|l|c|}
\hline UF & Família ou pessoa & Número de mandatos \\
\hline GO & Marconi Perillo (PSDB) & 4 \\
\hline AP & Waldez Góes (PDT) & 3 \\
\hline AM & Eduardo Braga (PPS, PMDB) & 3 \\
\hline SP & Geraldo Alckmin (PSDB) & 3 \\
\hline TO & Siqueira Campos (PP, PFL, PSDB) & 3 \\
\hline TO & Marcello Miranda (PFL, PMDB) & 3 \\
\hline ES & Paulo Hartung (PSB, PMDB) & 3 \\
\hline MA & Roseana Sarney (PFL, PMDB) & 3 \\
\hline PA & Simão Jatene (PSDB) & 3 \\
\hline PI & Wellington Dias (PT) & 3 \\
\hline AC & Família Viana (PT) & 4 \\
\hline PE & Família Arraes (PSB) & 3 \\
\hline RR & Família Campos (PTB e PP) & 3 \\
\hline AP & Família Capiberibe (PSB) & 3 \\
\hline
\end{tabular}

Fonte: Elaboração própria com base em dados do TSE.

Não são poucos os casos em que há grande continuidade de governadores e famílias nos governos estaduais. No caso de Goiás, a eleição de 2014 marcou um recorde para um mesmo nome nesse período, com quatro vitórias de Marconi Perillo (PSDB). Outros nove governadores também mantiveram grande sucesso local, com a conquista de três vitórias para o cargo. Ainda que existam casos em que o candidato tenha 
permanecido no mesmo partido e tenha uma importante história partidária, como o caso de Geraldo Alckmin e Simão Jatene pelo PSDB e Wellington Dias pelo PT, em muitos casos, há migração partidária, em que o nome do governador parece importar mais do que as legendas - típico caso de Siqueira Campos no Tocantins. O estado do Tocantins, aliás, juntamente com o do Amapá, aparece como aquele onde a disputa é altamente concentrada em dois grupos políticos claros, mostrando fraca pluralidade eleitoral. $O$ PMDB, com cinco casos, e o PSDB, com quatro, são as organizações partidárias que mais sustentam os governadores com muitos mandatos. Esse número também reflete o fato de que são as duas legendas com maior número de governadores desde a redemocratização.

Quanto às famílias identificadas, causa certo estranhamento a alta participação de partidos de esquerda (PT e PSB). Outrora, o discurso era de que tais "famílias" políticas pertenciam ao campo ideológico da "direita", como o exemplo dos Magalhães na Bahia e dos Sarney no Maranhão. Embora não tenha o mesmo sobrenome do avô, Miguel Arraes, Eduardo Campos era seu herdeiro político em Pernambuco.

A análise de todos os dados até aqui, sem dúvida, demonstra certo grau de continuísmo de grupos político-partidários entre os governos estaduais. São vários os casos em que a oposição genuína tem tido dificuldade de desafiar o partido incumbent. Muitas vezes a oposição local, além de enfrentar nomes fortes na disputa estadual, também enfrenta famílias com hegemonia local, dificultando a rotatividade de governadores. Caso existam estudos mais aprofundados sobre as coalizões estaduais, a oposição aos governadores, provavelmente, é uma opção pouco provável para a maioria das legendas (Abrucio, 1998; Melo, Pereira e Werneck, 2010). Não obstante o importante grau de governismo, são muitos os nomes novos entre os governos estaduais. Em média, os partidos políticos ficam menos de sete anos nos governos subnacionais. A própria reeleição não é tão comum como se costuma afirmar. Destarte, os sistemas políticos subnacionais ainda carecem de maiores estudos para que se possa chegar a um mínimo consenso sobre a real necessidade de alterações institucionais. Alguns elementos são contraditórios, impondo restrições a visões definitivas.

\section{Considerações finais}

No Brasil, os partidos políticos têm demonstrado uma vocação governista, preferindo ir ao encontro de governos a se opor a eles. Questiona-se o quanto a dependência de recursos estatais, como a patronagem, pode favorecer tal comportamento na medida em que existem mudanças claras nas orientações partidárias das últimas décadas (Mair, 1997; Blyth e Katz, 2005; Peres, 2014). A forte proximidade de partidos políticos com a esfera do Estado tão pouco é novidade no pensamento brasileiro. Se a sociedade civil ainda é conectada com os partidos políticos, tal 
A DISPUTA NOS GOVERNOS ESTADUAIS (1994-2014): A BATALHA ENTRE INCUMBENTS E OPOSIÇÃO

intermediação é entrecortada pela participação do Estado, entidade tão desejada pela elite política brasileira (Leal, 2012).

Tal inclinação governista fez alguns autores se perguntarem qual o papel da oposição no país (Meira, 2012; Rebello, 2013; Peres, 2014; Carvalho e Figueiredo Filho, 2014), temendo que o sistema político desestimulasse os partidos políticos derrotados em pleitos executivos em se satisfazer, ou até mesmo sobreviver, na oposição (Santos, 2006). Não obstante tais problemas, a oposição, ainda assim, possui algumas garantias e prerrogativas capazes de desafiar o Executivo (Bezerra, 2012).

Quanto às unidades subnacionais, o domínio exercido pelos governadores já foi alvo de pesquisas, com interpretações bem divergentes (Melo, Pereira e Werneck, 2010; Inácio e Amaral, 2013). Nesse caso, existe uma parte da ciência política que compreende como forte a sua influência (Abrucio, 1998).

Diante de tais perspectivas, um banco de dados com todas as eleições para governos estaduais desde 1994 foi criado e os principais resultados foram os seguintes: a) apesar de a maioria dos governadores obter êxito na reeleição quando se recandidata, uma outra parte, bastante significativa, não tenta nova eleição, culminando com uma alta taxa de renovação; b) o desempenho dos governadores reeleitos é similar ao desempenho de governadores eleitos quando não há candidato incumbent na disputa; c) boa parte das candidaturas vitoriosas apresenta um elevado grau de continuidade partidária em relação à candidatura prévia, e se estima que esse número deva ser bem maior, já que as coalizões de governo reúnem um conjunto elevado de partidos infelizmente pesquisas com esses dados ainda são raras; d) alguns partidos têm tido sucesso ao permanecer no poder quando conquistam os governos estaduais, tendo o PSDB o maior sucesso entre todos, por outro lado, sua conquista como membro exógeno do governo tem sido fraca; e) a região Nordeste é aquela na qual os partidos estaduais mais conseguem permanecer no poder, a região Sul, por sua vez, apresenta alta dificuldade de continuidade no poder, principalmente em função do caso extremo gaúcho, que historicamente tem eleito a oposição; f) algumas famílias e personalidades políticas possuem grande capital político local, mostrando como o personalismo e o familismo ainda fazem parte da história política brasileira.

O que falta à ciência política para compreender melhor os processos descritos neste artigo? Primeiramente, é mais do que necessário constituir um espaço de pesquisa específico para unidades subnacionais. Ainda não há, por exemplo, um banco de dados que disponha sobre quais partidos políticos ocupam secretarias nos governos estaduais ou sobre a votação nominal das bancadas nas Assembleias. Evidente que já existem estudos em alguns estados e municípios, porém, falta uma compilação de dados com uniformidade metodológica que permita comparações entre diferentes unidades da federação de modo sistemático. Também falta à disciplina compreender melhor quais são os instrumentos disponíveis aos partidos para que eles possam sobreviver organizacionalmente. Neste artigo, mostra-se como a função governativa é importante para as legendas mais relevantes do país. No entanto, não se demonstrou quais os 
incentivos existentes na relação entre partido e governo - status, políticas públicas, corrupção, recursos financeiros, cargos etc.

Todos os dados desenvolvidos até aqui devem ser vistos com cautela em relação a eventuais mudanças institucionais. Em primeiro lugar, o instituto da reeleição, criado em 1997, produz o efeito positivo de permitir a punição ou recompensa imediata para um chefe de Executivo, o que fortalece a accountability. Desse modo, acabar com a reeleição, embora produza um maior equilíbrio na competição, pode não compensar a perda do caráter de responsabilização. Em segundo lugar, o que parece mais evidente, é a continuidade de partidos políticos no poder. Os incentivos em pertencer a uma coalizão fazem com que muitos partidos almejem uma proximidade com postos governamentais. Tal interpretação carece de estudos mais aprofundados. Todavia, caso o diagnóstico se confirme, caberá ao sistema político dar uma reposta mais satisfatória a quem ocupa a função de oposição no parlamento, afastando oposições externas ao jogo democrático que podem levar a crises com efeitos perversos.

Maurício Michel Rebello - Doutor em Ciência Política pela Universidade Federal do Rio Grande do Sul e professor adjunto da Universidade Federal da Fronteira Sul, campus Erechim. E-mail: <mmrebello@yahoo.com.br>.

\section{Referências bibliográficas}

ABRUCIO, F. Os barões da federação: os governadores e a redemocratização brasileira. São Paulo: Hucitec/USP, 1998.

AMES, B. Os entraves da democracia no Brasil. Rio de Janeiro: Editora FGV, 2003.

AMORIM Neto, O. O Poder Executivo: centro de gravidade do sistema político brasileiro. In: AveLAR, L.; CinTRA, A. Sistema político brasileiro: uma introdução. Rio de Janeiro: Konrad-Adenauer-Stiftung; São Paulo, Unesp, 2007.

ARRETCHE, M. Estado federativo e políticas sociais: determinantes da descentralização. Rio de Janeiro: Revan; São Paulo: Fapesp, 2000.

AvelAR, L.; WALTeR, M. "Lentas mudanças: o voto e a política tradicional". Opinião Pública, Campinas, vol. 14, no 1 , p. $96-122,2008$.

BEZERRA, G. "A oposição nos governos FHC e Lula: um balanço da atuação parlamentar na Câmara dos Deputados". Dissertação de mestrado em Ciência Política. IFCH/UFRGS, Porto Alegre, 2012.

BLYTH, M.; KATZ, R. "From catch-all politics to cartelization: the political economy of the cartel party". West European Politics, vol. 28, n 1, p. 33-60, 2005.

Brambor, T.; Ceneviva, R. "Reeleição e continuísmo nos municípios brasileiros". Novos Estudos Cebrap, São Paulo, no 93, p. 9-21, 2012.

CARDello, A. "La reeleccion inmediata del Ejecutivo a nível subnacional. Um estudio de tres casos". Tese de doutorado em Ciência Política. IFCH/UFRGS, Porto Alegre, 2009. 
CARREIRÃO, Y.; Do NASCIMENTO, F. "As coligações nas eleições para os cargos de governador, senador, deputado federal e deputado estadual no Brasil (1986/2006)". Revista Brasileira de Ciência Política, Brasília, no 4, p. 75-104, 2010.

CARVAlho, N. E no início eram as bases: geografia política do voto e comportamento legislativo no Brasil. Rio de Janeiro: Revan, 2003.

CARVAlho, E.; Figueiredo Filho, D. Entre Hermes e Themis: a oposição e suas estratégias no presidencialismo de coalizão. In: DANTAS, H.; TOLEDO, J.; TEIXEIRA, M. (orgs.). Análise política e jornalismo de dados. Rio de Janeiro: Editora FGV, 2014.

CONCEIÇÃO, S.; AMARAL, R. "Execução orçamentária municipal e probabilidade de reeleição". In: Anais do XXXIII Encontro Nacional de Engenharia de Produção, Salvador, 2013.

DAHL, R. Poliarquia: participação e oposição. São Paulo: Editora da USP, 1997.

DUVERger, M. Os partidos políticos. Rio de Janeiro: Zahar, 1970.

EPITÁCIO, S.; RESENDE, R. De governista por excelência a oposição: o declínio eleitoral do PFL/DEM na Câmara Federal brasileira de 1998 a 2010. In: GALLO, C.; SouZA, B.; MARTINS, J. Ciência política hoje. Porto Alegre: Evangraf, 2013.

Figueiredo, A.; Limongi, F. Executivo e Legislativo na nova ordem constitucional. Rio de Janeiro: Editora FGV, 1999.

HALL, P.; TAYLOR, R. As três versões do neoinstitucionalismo. Lua Nova, São Paulo, n 58, p. 193223, 2003.

HUNTER, W.; POWER, T. Recompensando Lula: Poder Executivo, política social e as eleições brasileiras de 2006. In: Melo, C.; SÁEz, M. (orgs.). A democracia brasileira: balanço e perspectivas para o século 21. Belo Horizonte: Editora UFMG, 2007.

INÁCIO, M.; AMARAL, E. "Government or opposition? The determinants of legislative support for governors in Brazil". Sage Open, vol. 3, n 3, p. 1-11, 2013.

KInzo, M. Radiografia do quadro partidário brasileiro. São Paulo: Fundação Konrad-AdenauerStiftung, 1993.

KIRCHHEIMER, O. "The transformation of the Western European party systems". In: LAPALOMBARA, J.; Weiner, M. Political parties and political development. New Jersey: Princeton University Press, 1966.

KRAUSE, S.; GodoI, P. Coligações eleitorais para os Executivos estaduais (1986-2006): padrões e tendências. In: KRAUSE, S.; DANTAS, H.; MiguEL, L. (orgs.). Coligações partidárias na nova democracia brasileira: perfis e tendências. Rio de Janeiro: Fundação Konrad; São Paulo: Adenauer/Unesp, 2010.

Krause, S.; Rebello, M.; Silva, J. "O perfil do financiamento dos partidos brasileiros (2006-2012): o que as tipologias dizem?". Revista Brasileira de Ciência Política, no 16, p. 247-272, 2015.

LAMOUNIER, B. Presidencialismo ou parlamentarismo: perspectivas sobre a reorganização institucional brasileira. São Paulo: Loyola, 1993.

Lavareda, A. Principais marcas das eleições municipais de 2008. In: Lavareda, A.; Telles, H. (orgs.). Como o eleitor escolhe seu prefeito. Rio de Janeiro: FGV, 2011.

LEAL, V. Coronelismo, enxada e voto. São Paulo: Companhia das Letras, 2012.

LIMA JR., O. Democracia e instituições políticas no Brasil dos anos 80. São Paulo: Edições Loyola, 1993. 
MAURÍCIO MICHEL REBELLO

MAInWARING, S. Sistemas partidários em novas democracias: o caso do Brasil. Porto Alegre: Mercado Aberto, Rio de Janeiro: FGV, 2001.

MAinWARING, S.; SCULly, T. "A institucionalização dos sistemas partidários na América Latina". Dados, Rio de Janeiro, vol. 37, no 1, p. 43-79, 1994.

Mainwaring, S.; Meneguello, R.; Power, T. Partidos conservadores no Brasil contemporâneo. São Paulo: Paz e Terra, 2000.

MAIR, P. Party system change. Clarendon Press: Oxford, 1997.

MANin, B. "As metamorfoses do governo representativo". Revista Brasileira de Ciências Sociais, São Paulo, vol. 10, no 29, p. 5-34, 1995.

MARENCO, A. Desempenho eleitoral, voto partidário e responsabilização nas eleições legislativas brasileiras. In: INÁCIO, M.; RenNó, L. (orgs.). Legislativo brasileiro em perspectiva comparada. Belo Horizonte: UFMG, 2009.

MeIRA, J. "Vale a pena ser oposição no Brasil?". Em Debate, Porto Alegre, vol. 4, no 1, p. 20-25, 2012.

Melo, M.; Pereira, C.; Werneck, H. C. "Delegation dilemmas: coalition size, electoral risk, and regulatory governance in new democracies". Legislative Studies Quarterly, vol. 35, p. 31-56, 2010.

MoIsÉS, J. "Desempenho do Congresso Nacional no presidencialismo de coalizão (1995/2006)". Cadernos Adenauer, vol. 2, p. 15-32, 2011.

Nicolau, J. Voto personalizado e reforma eleitoral no Brasil. In: SOARES, G.; RenNó, L. (orgs.). Reforma política: lições da história recente. Rio de Janeiro: Editora FGV, 2006.

NoRRIS, P. Driving democracy. New York: Cambridge University Press, 2008.

O’DonnelL, G. Delegative democracies. Notre Dame: Kellogg Institute, 1992.

PALERMO, V. "Como se governa o Brasil? O debate sobre instituições políticas e gestão de governo". Dados, Rio de Janeiro, vol. 43, no 3, p. 521-557, 2000.

PAnebianco, A. Modelos de partido: organização e poder nos partidos políticos. São Paulo: Martins Fontes, 2005.

Peres, P. O governismo na política brasileira. In: DANTAS, H.; Toledo, J.; TeiXeira, M. (orgs.). Análise política e jornalismo de dados. Rio de Janeiro: FGV, 2014.

POWELL, B. Elections as instruments of democracy: majoritarian and proportional visions. New Haven, Londres: Yale University Press, 2000.

ReBeLLo, M. "Partidos e governos nas sombras: clareza de responsabilidade, responsabilização eleitoral e sistema partidário no Brasil". Tese de doutorado em Ciência Política. IFCH/UFRGS, Porto Alegre, 2013.

SAMUELS, D. "Presidencialism and accountability for the economy in comparative perspective". American Political Science Review, vol. 98, no 3, p. 425-436, 2004.

SAntos, F. O Poder Legislativo no presidencialismo de coalizão. Belo Horizonte: Editora UFMG, 2003.

SAnTos, F. Em defesa do presidencialismo de coalizão. In: SOARES, G.; RenNó, L. (orgs.). Reforma política: lições da história recente. Rio de Janeiro: FGV, 2006. 
A DISPUTA NOS GOVERNOS ESTADUAIS (1994-2014): A BATALHA ENTRE INCUMBENTS E OPOSIÇÃO

SANTOS, F. (org.). O Poder Legislativo nos estados: diversidade e convergência. Rio de Janeiro: Editora FGV, 2001.

Santos, F.; CANello, J. "O governo Dilma na Câmara dos Deputados: comparando partidos e coalizões nos mandatos petistas". Nota de pesquisa. Necon, 2014.

TAROUCO, G.; MADEIRA, R. "Os partidos brasileiros segundo seus estudiosos: análise de um expert survey". Civitas, Porto Alegre, vol. 15, n 1, p. 24-39, 2015.

TAYLOR, M.; DA ROS, L. "Os partidos dentro e fora do poder: a judicialização como resultado contingente da estratégia política". Dados, Rio de Janeiro, vol. 51, no 4, p. 825-864, 2008.

WOLINETZ, S. "Beyond the catch-all party: approaches to the study of parties and party organization in contemporary democracies". In: GunTHeR, R.; MonTERo, J.; Linz, J. Political parties: old concept and new challenges. Oxford: Oxford University Press, 2002.

\section{Resumo}

A disputa nos governos estaduais (1994-2014): a batalha entre incumbents e oposição

O jogo entre governo e oposição sempre foi algo amplamente discutido na ciência política. Trabalhos recentes indicam que o sistema partidário de alguns países tem forte inclinação pró-governo, enfraquecendo a oposição partidária. Atualmente, no Brasil, discute-se como reduzir o poder de chefes do Executivo, como a recente proibição da reeleição imediata realizada pela Câmara dos Deputados. Neste artigo, propôs-se uma discussão sobre a força dos governos e dos desafiantes nas eleições para governos estaduais. Todas as eleições, desde 1994, foram analisadas a partir de dados do TSE em todas as unidades da federação. Os resultados indicam que o instituto da reeleição não causa uma barreira instransponível para aqueles que desafiam o governador. Porém, ao mesmo tempo, os dados sugerem uma relativa continuidade dos partidos políticos a nível estadual. Além disso, a ideia de que o Poder Executivo tem grande capacidade de atração sobre os partidos políticos não pode ser desconsiderada.

Palavras-chave: eleições; eleições estaduais; reeleição; oposição; governos estaduais

\section{Abstract}

The dispute among state governments (1994-2014): the battle between incumbents and opposition

The game between government and opposition is something that has always been widely discussed in political science. Recent studies indicate that party systems may have a strong pro-government bias, weakening opposition parties. How to limit the power of executive leaders is a key question in Brazil, as suggested by the recent ban on immediate re-election enacted by the Chamber of Deputies. In this paper, we propose a debate about the relative power of incumbent governors and challengers in state government elections. All elections since 1994 were analyzed using TSE data from all Brazilian states. The results indicate that re-election does not impose an insurmountable barrier to those who challenge the governor. At the same time, the data suggest a relative continuity of political parties at the state level. Moreover, the idea that the Executive branch has a great ability to appeal to political parties cannot be disregarded.

Keywords: elections; state elections; re-election; opposition; state government 


\section{Resumen}

La disputa en gobiernos estatales (1994-2014): la batalla entre los gobiernos y la oposición

El juego entre el gobierno y la oposición siempre ha sido algo ampliamente discutido en la ciencia política. Estudios recientes indican que el sistema de partidos en algunos países tiene una fuerte inclinación a favor del gobierno, lo que debilita al partido de la oposición. Actualmente, en Brasil, se discute cómo reducir el poder de los jefes ejecutivos, como la reciente prohibición de la reelección inmediata en el poder de la Cámara de diputados. En este artículo, hemos propuesto un debate sobre el poder de los gobiernos y de los desafiantes en las elecciones para los gobiernos estatales. Todas las elecciones han sido analizadas desde 1994 a partir de datos del TSE en todas las unidades de la federación. Los resultados indican que el instituto de la reelección no causa una barrera insuperable para aquellos que desafían al gobernador. Pero, al mismo tiempo, los datos sugieren una continuidad relativa de los partidos políticos a nivel estatal. Por otra parte, la idea de que el poder ejecutivo tiene una gran capacidad para atraer a los partidos políticos no puede pasarse por alto.

Palabras clave: elecciones; elecciones estatales; reelección; oposición; gobiernos de los estados

\section{Résumé}

Le litige dans les gouvernements des états (1994-2014): la bataille entre les gouvernements et l'opposition

Le jeu entre le gouvernement et l'opposition a toujours été largement discuté dans la science politique. Des études récentes indiquent que le système des partis dans certains pays a une forte inclination pro-gouvernementale, ce qui affaiblit les partis d'opposition. Actuellement, au Brésil, on étudie la façon de réduire la force des chefs du pouvoir exécutif, comme dans le cas de l'interdiction récente de réélection immédiate réalisée par la Chambre des députés. Dans cet article, nous avons proposé une discussion sur la force des gouvernements et de leurs rivaux aux élections visant le gouvernement des états. Toutes les élections depuis 1994 ont été analysées à partir des données du TSE dans toutes les unités de la fédération. Les résultats indiquent que le fait d'instituer la réélection ne provoque pas un obstacle insurmontable pour ceux qui défient le gouverneur. En même temps, les données suggèrent cependant une continuité relative des partis politiques au niveau des états. De plus, l'idée que le pouvoir exécutif a une grande capacité de faire appel aux partis politiques ne peut être négligée.

Mots-clés: élections; élections d 'états; réélection; opposition; gouvernements d 'états

Artigo submetido à publicação em 6 de julho de 2015 .

Versão final aprovada em 13 de março de 2017. 